Original Research Article

\title{
Computer assisted learning versus conventional teaching: a questionnaire based study
}

\author{
Shipra Jain*, Kopal Sharma, Pushpawati Jain, Sakshi Singh
}

Department of Pharmacology, Mahatma Gandhi Medical College and Hospital, RIICO Institutional Area, Sitapura, Tonk Road, Jaipur 302022, Rajasthan, India

Received: 21 March 2017 Accepted: 22 April 2017

\section{*Correspondence to: \\ Dr. Shipra Jain, \\ Email: dr.shiprajain@ yahoo.com}

Copyright: (C) the author(s), publisher and licensee Medip Academy. This is an openaccess article distributed under the terms of the Creative Commons Attribution NonCommercial License, which permits unrestricted noncommercial use, distribution, and reproduction in any medium, provided the original work is properly cited.

\begin{abstract}
Background: Animal experiments have ethical concerns thus practical sessions mean demonstration classes. Incorporation of novel teaching methods in pharmacology is the need of the hour when there is extensive use of computers among students. The present study was conducted to analyse and compare the knowledge gained by students through traditional demonstration lectures versus Computer assisted learning (CAL) sessions.

Methods: This study was done on 112 second professional MBBS students after taking informed consent. They were divided in 2 groups viz. CAL group and Traditional teaching group and were taught experimental pharmacology topics using different teaching methods. The performance of the students in the two groups was then compared based on questionnaire. Student's perception on use of CAL was also assessed.

Results: A statistically significant difference in performance was seen among the students in the traditional teaching group and CAL group. In CAL group, the average scores for the Rabbit's eye, Dog's blood pressure, Animals used in Experimental Pharmacology and Screening methods sessions were 9.07, 8.3 and 3.8 respectively while in traditional teaching group the scores were 8.4, 7.8 and 3.4 respectively. Similarly, in frog's heart session, CAL group scored higher (7.14) than traditional group (6.79). $76.8 \%$ students strongly agreed that CAL sessions were useful and $100 \%$ students strongly agreed that traditional lectures are difficult to retain.

Conclusions: The study concludes that CAL is a promising teaching option when compared to traditional demonstration lectures for undergraduate practical pharmacology classes.
\end{abstract}

Keywords: Animal experiments, Computer assisted learning, Demonstrations, Undergraduate, Practicals

\section{INTRODUCTION}

Pharmacology is an ever evolving subject marked by perpetual updates. The undergraduate curriculum in pharmacology must be suitable, clinically oriented and helpful in making decisions in therapeutics. ${ }^{1}$ Undergraduate teaching in pharmacology involves theory and practical sessions. The practical exercises in pharmacology have been a matter of debate since long. The practical classes comprising of animal experiments were regarded to be irrelevant by medical students, teachers and policy makers since the learning goals mainly involve cognitive domain rather than psychomotor domain., ${ }^{2,3}$ Animals have been extensively used in the past to demonstrate the effect of various drugs in experimental pharmacology classes in the laboratory.
In fact, most of the drug discoveries have been possible due to research involving animals in the past. ${ }^{4}$ However, there has been a gradual decline in live animal experiments in medical colleges in India. ${ }^{5}$ Animal experiments are tedious and have several practical constraints. ${ }^{6}$ Availability of animals, maintenance of an animal house and ethical clearance being some of them. Due to multiple limiting factors with the use of animals for academic purpose, the only method available for teachers remains the conventional chalk and board type. But such method is not appreciated for practical sessions since the students are unable to visualize the experiments.

Thus, there is a need to develop alternatives to animal experiments. Ethical issues in animal use and rapid emergence of computer technology has resulted in newer 
methods of teaching and learning like computer assisted learning. ${ }^{6}$ In the present era of digital revolution, Computer assisted learning (CAL) software seems to be a promising option which enables the student to visualize live animal experiments on a computer screen. A number of studies have been conducted earlier which conclude the effectiveness of CAL as a reliable method of teaching. But most of the studies have included only few topics of the teaching curriculum. The present study has been conducted with the aim to include a multitude of topics to evaluate and compare the overall performance of the students by traditional didactic lectures versus CAL in teaching experimental pharmacology.

\section{METHODS}

The present study was conducted on MBBS second professional students. Ethical approval was taken before starting the study. The participants were explained about the entire procedure and an informed consent was obtained. All the students of MBBS second professional who were willing to participate were included in the study. A total of 112 students were enrolled for the study. They were then randomly divided into two groups viz. CAL group and Traditional teaching group of 56 students each.

\section{Study design}

This is a questionnaire based study. A pre-test was performed to validate the questionnaire. The study was conducted during 4 consecutive practical classes. The topics included in our study were Effect of drugs on rabbit eye, Effect of drugs on blood pressure of dog, Common animals used in experimental pharmacology, Screening methods for Analgesic and Antiepileptic drugs and Effect of various drugs on frog's heart. One group of students was taught each of the above topics using CAL software while the other group was taught the same topics by traditional didactic lectures using chalk and board.

The software used was Expharm Pro and Excology Pro Animal Simulator - Pharmacology developed by Elsevier India - A Division of Relx India Private Limited. On first day, both the groups were taught about the effects of various drugs on rabbit eye for 1 hour using different teaching methods. This was followed by a test comprising of 10 multiple choice questions relevant to the topic covered. The students were given 10 minutes to attempt the questions independently.

The same process was followed for the other topics viz. Effect of different drugs on dog's blood pressure in the next practical class, common animals used in experimental pharmacology (EP) and screening methods were taught together in the subsequent practical class while effect of various drugs on frog's heart were covered in the fourth practical class.
The performance of the students among the two batches was then compared and analysed. In the last practical class, the perception of all the students on CAL as a teaching method in experimental pharmacology was analysed using a 5-point Likert scale (ranging from strongly disagree to strongly agree) as depicted in the flow chart (Figure 1).

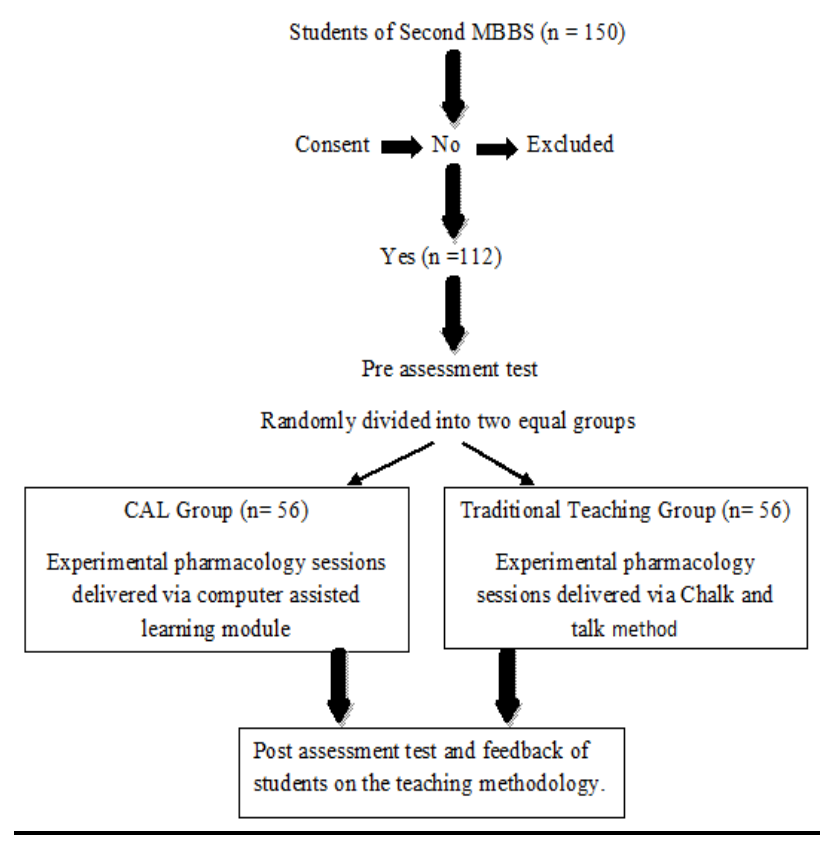

Figure 1: Flow chart of study design.

\section{Statistical analysis}

The mean scores along with the standard deviation was calculated for both the CAL group as well as traditional teaching group and tested for significance. The collected data was analysed using (SPSS for Windows, version 16.0 Chicago, SPSS Inc.), Excel 2010 with statistical significance evaluated using two-sided $\mathrm{P}$ value at a $5 \%$ level of significance.

\section{RESULTS}

The mean score of students for Rabbit's eye session in CAL group was $9.07 \pm 1.02$ and it was statistically significant ( $p<0.0001)$ as compared to the group taught by traditional teaching method. Similarly, the students in CAL group obtained statistically significant scores in Dog's blood pressure ( $\mathrm{p}=0.0359)$, Common animals used in experimental pharmacology and Screening of drugs ( $p$ $<0.0001)$ and Frog's heart teaching session ( $p<0.0414)$ (Table 1).

In Rabbit's eye session, the average score in CAL group was 9.07 while it was 8.18 in traditional teaching group. $44.6 \%$ students scored $100 \%$ in CAL session as compared to traditional method where $100 \%$ scorers were merely $19.64 \%$ (Figure 2). 
Table 1: Comparison of mean scores between computer assisted learning $(n=56)$ versus Traditional teaching group $(\mathbf{n}=56)$ for various sessions.

\begin{tabular}{|lllll|}
\hline Session & Groups & Mean & Standard deviation & P value \\
\hline \multirow{2}{*}{ Rabbit's eye } & CAL & 9.07 & 1.02 & $\mathrm{p}<0.0001$ \\
& Traditional & 8.18 & 1.25 & Highly significant \\
\hline \multirow{2}{*}{ Dog's blood pressure } & CAL & 8.32 & 1.08 & $\mathrm{p}=0.0359$ \\
& Traditional & 7.86 & 1.23 & Significant \\
\hline Animals used in experimental & CAL & 7.63 & 0.59 & $\mathrm{p}<0.0001$ \\
pharmacology and screening methods & Traditional & 6.96 & 0.87 & Highly significant \\
\hline \multirow{2}{*}{ Frog's Heart experiment } & CAL & 7.14 & 0.98 & $\mathrm{p}=0.0414$ \\
& Traditional & 6.79 & 0.85 & Significant \\
\hline
\end{tabular}

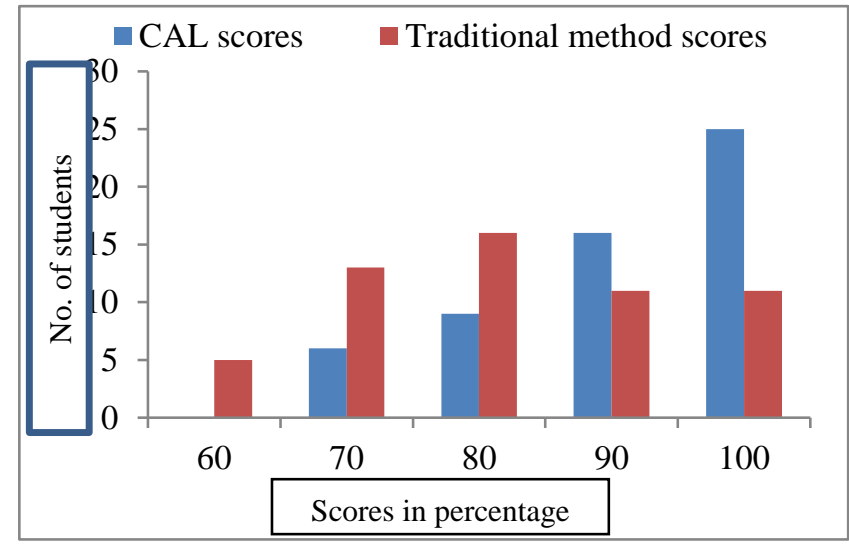

Figure 2: Distribution of the students according to percentage of scores for Rabbit's eye teaching session.

The average score in CAL group was 8.3 and traditional group had an average score of 7.8 in dog's blood pressure session (Figure 3).

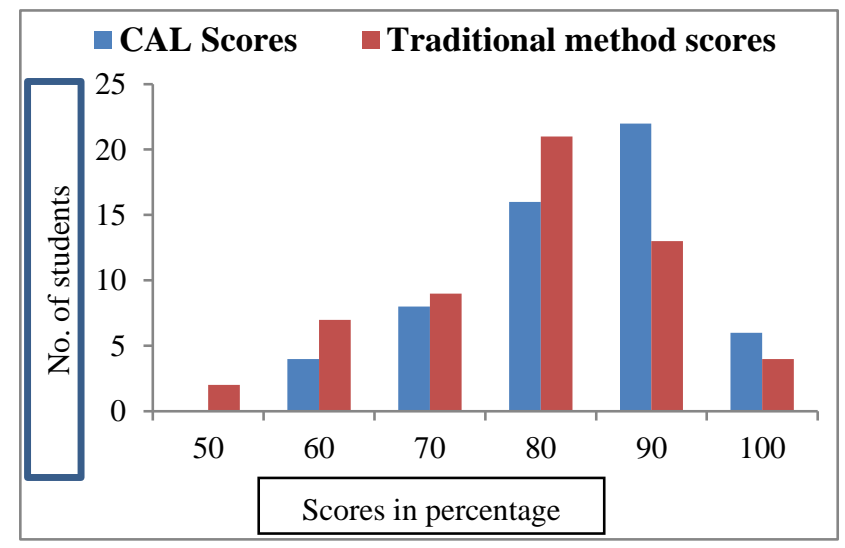

Figure 3: Distribution of the students according to percentage of scores for Dog's blood pressure teaching session.

CAL group had higher average score (7.63) than traditional group (6.96) for animals used in experimental pharmacology and screening of analgesic and antiepileptic drugs session (Figure 4).

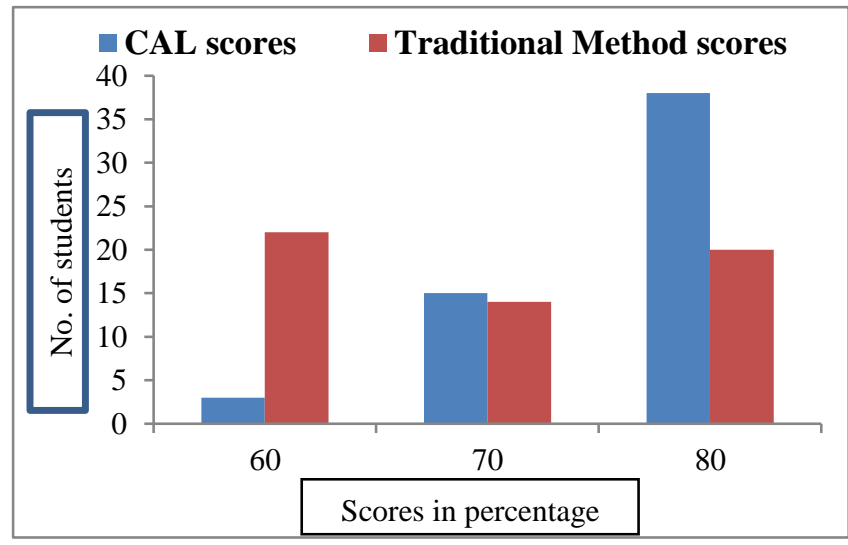

Figure 4: Distribution of the students according to percentage of scores for animals used in experimental

pharmacology and screening of drugs teaching session.

Similarly, the average score was 7.14 in CAL group while traditional group scored 6.79 for effect of various drugs on frog's heart teaching session (Figure 5).

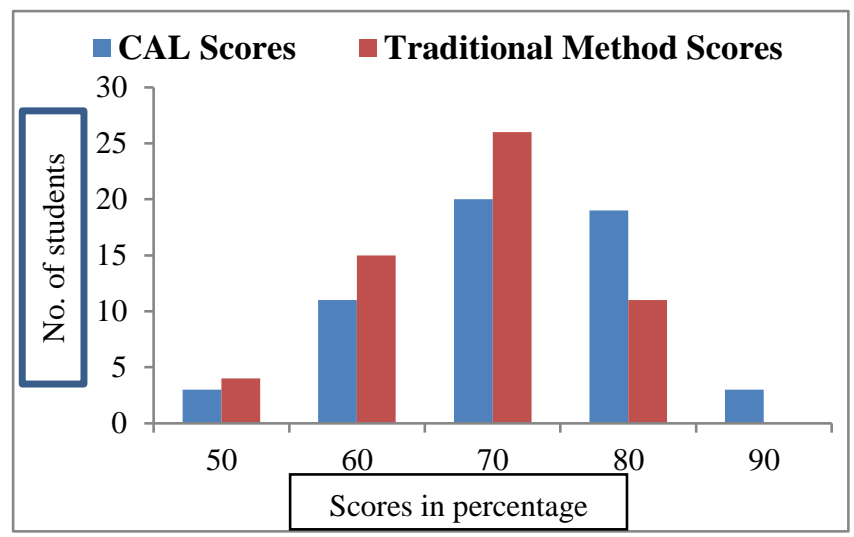

Figure 5: Distribution of the students according to percentage of scores for effect of drugs on Frog's heart teaching session.

The feedback of the students on the two training sessions further reflects that 43 students $(76.8 \%)$ strongly agree 
that session delivered through CAL were useful (Figure $6)$.

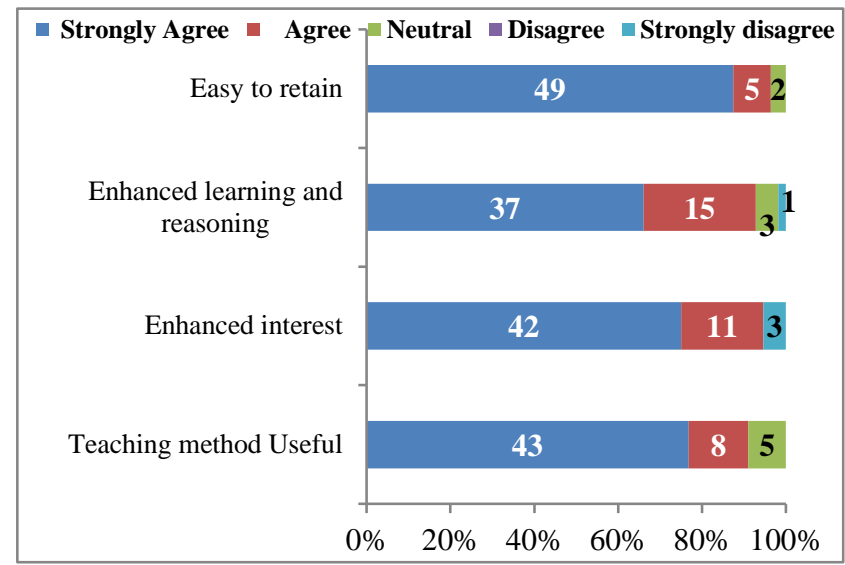

Figure 6: Perception of the students for computer assisted learning session in experimental pharmacology $(n=56)$.

All the students $(100 \%)$ strongly agreed that traditional teaching method was difficult to retain while merely $3.57 \%$ students in CAL group found it difficult to retain.

\section{DISCUSSION}

Since pharmacology as a subject is complex, it is imperative to include innovative teaching methods which can improve the performance of the students. Although practical sessions in pharmacology are indispensable, ultimately, they serve as a vehicle for successful inculcation of practical and animal handling skills. ${ }^{6}$ With extensive use of information technology in medical schools and availability of requisite resources for effective teaching and learning, it was realized that medical students need to be conversant with as well as possess expertise in computing skills. ${ }^{7}$

In the present study, the performance of the students was compared between CAL and traditional teaching method by giving a questionnaire at the end of teaching session on some topics of experimental pharmacology. It was observed that the students taught by CAL scored better as compared to students who were taught by the traditional methods. Our results were consistent with similar studies conducted earlier. ${ }^{8-10}$ The students realized that CAL helped in better understanding of the topic than the traditional teaching. The feedback of the students based on five-point Likert scale taken at the end of session showed that CAL is accepted as a useful method of teaching, learning and reasoning. It enhanced the interest of the students in the subject and the topics covered through CAL are easier to remember.

\section{Advantages of CAL}

The primary advantage of CAL is that it helps to achieve almost all of the learning objectives. ${ }^{6}$ This is because
CAL involves the cognitive domain of the student. The role of novel teaching methods such as CAL has been proved to be encouraging as demonstrated in several studies conducted in the past. ${ }^{11}$ Studies have shown that CAL is favourably accepted by the medical students in the curriculum and they are acquainted with computers since school level. ${ }^{8,9} \mathrm{CAL}$ helps to achieve a better theoretical understanding of animal experiments owing to the fact that simulations mimic the real experiments done in the laboratory. The student can observe the effects of various drugs in simulations and cumbersome practical exercises become interesting and simple to understand. It has the potential to raise the teaching standards to higher levels and it is inevitably profitable when time and availability of equipments are the limiting factors. ${ }^{12} \mathrm{CAL}$ module also helps to promote rational as well as evidence based utilization of medicines among the students. ${ }^{3,13,14}$

At times, it is not possible to demonstrate intricate details of the experiments to a large group of students and only effect of few drugs can be observed in a specific period of time. ${ }^{7,15-18}$ The size of the group of students involved in animal experiments depends upon the availability of animals. These limitations can be overcome with the introduction of CAL. The medical students if provided with CAL software can study and practice at their own speed, multiple times, as desired. ${ }^{19}$ Biological variations which are frequently encountered in animal experiments decreases the morale of the students and is time consuming for the students as well as the teachers involved. This is obviated in simulations done under CAL which are reproducible. CAL simulations can be repeatedly performed without any loss of animals and experimental errors. ${ }^{15,16}$ Reduction in the cost involved with animal experiments is another advantage.,15 The principle of 3 Rs viz. Reduction, Refinement and Replacement to facilitate humane animal use can be achieved with the implementation of CAL. There is documented evidence that computer simulations are more profitable than establishment and maintenance of animal houses. ${ }^{15,16,20,21}$

\section{Disadvantages of CAL}

CAL has certain drawbacks which should also be borne in mind. CAL provides a virtual environment for animal experiments and certain aspects of practical sessions remain unfulfilled. Preparation of physiological salt solutions of varied concentrations, proper experimental set up, drug administration to animals and monitoring of physiological signs during experiments cannot be performed by the students. ${ }^{2,7,16}$ There are preset doses in the simulations thus students fail to appreciate responses at varied doses. A major disadvantage of CAL is that it can be easily forgotten when compared to live animal experiments. ${ }^{15}$ The installation of this software package is expensive. Besides this, it is associated with technical problems. Technical snags are often encountered during CAL sessions and good technical support in mandatory. ${ }^{9}$ This holds especially true for faculty members who are 
not well versed with use of multimedia and require technical assistance.

\section{CONCLUSION}

The present study concludes that CAL is a reliable method of teaching and learning in experimental pharmacology for undergraduate medical students as compared to demonstration classes as it fulfils most of the learning goals. The limitations of animal experiments such as ethical issues, biological variability and nonreproducibility besides practical problems associated with availability of animals can be overcome by incorporation of CAL in the teaching curriculum in medical schools. Desired technical assistance must be provided to the teachers and in some cases, students so that the ultimate goal of effective teaching and learning may be achieved.

\section{Recommendations}

The present study aimed to evaluate whether CAL is an effective teaching and learning method in medical undergraduates. Similar studies should be conducted on postgraduate students and faculty members so that CAL becomes an integral part of the practical sessions in the present scenario when animal experiments cannot be performed and traditional lectures are futile. CAL laboratories should be set up in all medical schools with adequate training of faculty and technical staff for their smooth functioning.

\section{ACKNOWLEDGMENTS}

Authors would sincerely like to thank the Elsevier team who developed and provided the software with which the students learnt CAL.

Funding: No funding sources

Conflict of interest: None declared

Ethical approval: The study was approved by the Institutional Ethics Committee

\section{REFERENCES}

1. Vasundara K, Pundarikaksha HP, Vijendra R, Girish K, Jyothi R, Srinivasa P. Existing and expected practical medical pharmacology curriculum - A survey. J Clin Diag Res. 2011;5(2):340-3.

2. Dewhurst D. Is it possible to meet the learning objectives of undergraduate pharmacology classes with non-animal models? AATEX. 2008;14:207-12.

3. Hughes IE. Do computer simulations of laboratory practicals meet learning needs? Trends Pharmacol Sci. 2001;22:71-4.

4. Sharma D, Malhotra P. A comparison of computer assisted learning and practical animal experiments for undergraduate medical students in pharmacology curriculum- a questionnaire based study conducted in a medical college of North India. Int $\mathrm{J}$ Basic Clin Pharmacol. 2016;5:2581-4.
5. Badyal DK, Desai C. Animal use in pharmacology education and research: The changing scenario. Indian J Pharmacol. 2014;46:257-65.

6. John LJ. A review of computer assisted learning in medical undergraduates. J Pharmacol Pharmacother. 2013;4(2):86-90.

7. Dewhurst D. Computer-based alternatives to using animals in teaching physiology and pharmacology to undergraduate student. Altern Lab Anim. 2004;32:517-20.

8. Nettah S. Computer assisted learning (CAL) as ateaching learning method in teaching experimental pharmacology. Int $\mathrm{J}$ Basic Clin Pharmacol. 2014;3:63-5.

9. Govindaraja C, Prakash HJ, Annamalai C, Vedhavathy SS. Computer assisted learning: perceptions and knowledge skills of undergraduate medical students in a Malaysian Medical School. Natl J Physiol Pharm Pharmacol. 2011;1(2):63-7.

10. Gaikwad N, Tankhiwale S. Interactive E-learning module in pharmacology: a pilot project at a rural medical college in India. Perspect Med Edu. 2014;3(1):15-30.

11. Tikkoo D, Gupta M. Student's perception and experience of computer assisted learning as a teaching method in experimental pharmacology. Int $\mathbf{J}$ Basic Clin Pharmacol. 2015;4:1168-74.

12. Hounshell PB, Hill SR. The microcomputer and achievement and attitudes in high school biology. J Res Sci Teaching. 1989;26:543-9.

13. Wiecha JM. Collaborative online learning (COL): A new distance education methods. Essential Drug Monitor. 2003;33:36.

14. Hughes IE. Computer-based learning-an aid to successful teaching of pharmacology? Naunyn Schmiedebergs Arch Pharmacol. 2002;366:77-82.

15. Kuruvilla A, Ramalingam S, Bose AC, Shastri GV, Bhuvaneswari K, Amudha G. Use of computer assisted learning as an adjuvant to practical Pharmacology teaching: Advantages and limitations. Indian J Pharmacol. 2001;33:272-5.

16. Baby LT, Kavalakkat JC, Abraham S, Sathianarayanan S. CAL: A modern tool for Pharmacology. Internet $\mathrm{J}$ of Medical Simulation. 2009;2:2.

17. Markham T, Jones SJ, Hughes I, Sutcliffe M. Survey of methods of teaching and learning in undergraduate pharmacology within the UK higher education. Trends Pharmacol Sci. 1998;19:257-62.

18. Hughes I. Changes in the technological methods of teaching and learning in undergraduate pharmacology in UK Higher Education. J Biosci Edu. 2003;1(1):1.

19. Kamath A. A review of use of eLearning in pharmacology. Int J Integr Med Sci. 2015;2(9):15762.

20. Dewhurst DG, Hardcastle J, Hardcastle PT, Stuart E. Comparison of a computer simulation program and a traditional laboratory practical class for teaching the principles of intestinal absorption. Am J Physiol. 1994;267:S95-104. 
21. Leathard HL, Dewhurst DG. Comparison of cost effectiveness of a computer assisted learning program with tutored demonstration to teach intestinal motility to medical students. ALT-J. 1995;3:118-25.
Cite this article as: Jain S, Sharma K, Jain P, Singh S. Computer assisted learning versus conventional teaching: a questionnaire based study. Int J Basic Clin Pharmacol 2017;6:1399-404. 